\title{
On the effects of hydroxyl substitution degree and molecular weight on mechanical and water barrier properties of hydroxypropyl methylcellulose
} films

\author{
Caio G. Otoni ${ }^{\mathrm{a}, \mathrm{b}, *}$, Marcos V. Lorevice ${ }^{\mathrm{a}, \mathrm{c}}$, Márcia R. de Moura ${ }^{\mathrm{d}}$, Luiz H.C. Mattoso ${ }^{\mathrm{a}}$ \\ a Nanotechnology National Laboratory for Agriculture (LNNA), Embrapa Instrumentation - Rua XV de Novembro, 1452, São Carlos, SP, 13560-970, Brazil \\ ${ }^{\mathrm{b}}$ PPG-CEM, Department of Materials Engineering, Federal University of São Carlos - Rodovia Washington Luís, km 235, São Carlos, SP, 13565-905, Brazil \\ ${ }^{\mathrm{c}}$ PPGQ, Department of Chemistry, Federal University of São Carlos - Rodovia Washington Luís, km 235, São Carlos, SP, 13565-905, Brazil \\ d Department of Physics and Chemistry, FEIS, São Paulo State University - Av. Brasil, 56, Ilha Solteira, SP, 15385-000, Brazil
}

\section{A R T I C L E I N F O}

Chemical compounds studied in this article: Hydroxypropyl methylcellulose (PubChem CID: 57503849)

Keywords:

Biopolymer

Cellulose derivative

Cellulose ether

Hypromellose

Food packaging

Edible film

\begin{abstract}
A B S T R A C T
In line with the increasing demand for sustainable packaging materials, this contribution aimed to investigate the film-forming properties of hydroxypropyl methylcellulose (HPMC) to correlate its chemical structure with film properties. The roles played by substitution degree (SD) and molecular weight $\left(\mathrm{M}_{\mathrm{w}}\right)$ on the mechanical and water barrier properties of HPMC films were elucidated. Rheological, thermal, and structural experiments supported such correlations. SD was shown to markedly affect film affinity and barrier to moisture, glass transition, resistance, and extensibility, as hydroxyl substitution lessens the occurrence of polar groups. $\mathrm{M}_{\mathrm{w}}$ affected mostly the rheological and mechanical properties of HPMC-based materials. Methocel ${ }^{\circ}$ E4 M led to films featuring the greatest tensile strength (ca., $67 \mathrm{MPa}$ ), stiffness (ca., $1.8 \mathrm{GPa}$ ), and extensibility (ca., 17\%) and the lowest permeability to water vapor $\left(c a ., 0.9 \mathrm{~g} \mathrm{~mm} \mathrm{kPa}^{-1} \mathrm{~h}^{-1} \mathrm{~m}^{-2}\right.$ ). These properties, which arise from its longer and less polar chains, are desirable for food packaging materials.
\end{abstract}

\section{Introduction}

Recently, there has been an increasing trend towards the use of biopolymers as film-forming materials (e.g., for food packaging applications) in an effort to reduce the environmental problems arising from the unrestricted exploitation of fossil fuels and the inadequate disposal of non-biodegradable materials (Azeredo \& Waldron, 2016; Garavand, Rouhi, Razavi, Cacciotti, \& Mohammadi, 2017). Cellulose is a widely available homopolysaccharide. It is made up of $\beta$-D-glucopyranoside units, linked by 1,4-glycosidic bonds, and arranged as long, linear, unbranched chains. These aspects, in addition to high occurrence of hydroxyl groups - three per anhydroglucose ring - provide cellulose with extremely strong intermolecular interactions, which in turn result in fibrous aspect and high stiffness as well as in infusibility and insolubility in water and most organic solvents (Zhang, Zhang, Tian, Zhou, \& Lu, 2013), characteristics that are undesirable from the polymer processing standpoint.

In order to increase the processability of cellulose as a film-forming matrix, cellulose derivatives have been produced by the partial substitution of hydroxyl groups by bulkier, less reactive groups. Different cellulose ethers have been demonstrated to be suitable film-forming matrices for food packaging applications, including methylcellulose (Bertolino et al., 2016), hydroxypropyl cellulose (Cavallaro, Donato, Lazzara, \& Milioto, 2011; Cavallaro, Lazzara, Konnova, Fakhrullin, \& Lvov, 2014), and hydroxypropyl methylcellulose (HPMC) (Alzate, Miramont, Flores, \& Gerschenson, 2017; Moghimi, Aliahmadi, \& Rafati, 2017). HPMC stands out because it is also water soluble, odorless, tasteless (Burdock, 2007), generally recognized as safe (GRAS) by the United States Food and Drug Administration (US FDA) (GRAS Notice No. GRN 000213, 2007), and allowed for direct (e.g., as an additive) and indirect (e.g., as a food-contacting packaging material) food applications by US FDA (21 CFR 172.874, 2011) and European Union

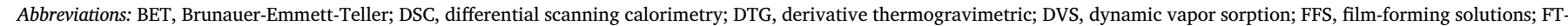

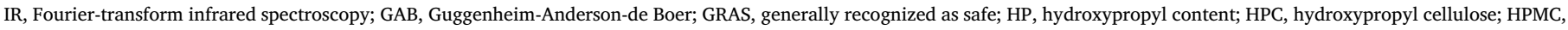

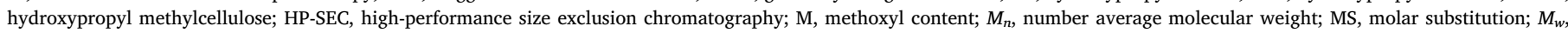

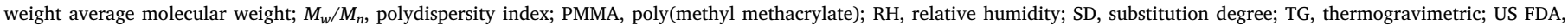
United States Food and Drug Administration; WVP, water vapor permeability

* Corresponding author at: Nanotechnology National Laboratory for Agriculture (LNNA), Embrapa Instrumentation - Rua XV de Novembro, 1452, São Carlos, SP, 13560-970, Brazil.

E-mail addresses: cgotoni@gmail.com (C.G. Otoni), marcos.lorevice@gmail.com (M.V. Lorevice), marcia@dfq.feis.unesp.br (M.R.d. Moura), luiz.mattoso@embrapa.br (L.H.C. Mattoso). 
(EPCD No. 95/2/EC, 1995). These characteristics allowed HPMC to be used as matrix for edible films (Otoni et al., 2017), tablets (Zhang et al., 2017), and oral-disintegrating sheets (Borges, Silva, Coelho, \& Simões, 2015). It is produced upon etherification reactions among alkaline cellulose and methyl chloride and propylene oxide, leading to the replacement of hydroxyl groups by methoxyl $\left(-\mathrm{OCH}_{3}\right)$ and hydroxypropyl $\left(-\mathrm{OCH}_{2} \mathrm{CH}(\mathrm{OH}) \mathrm{CH}_{3}\right)$ ones, respectively (Burdock, 2007; Keary, 2001). The average number of hydroxyl groups replaced by methoxyl groups in an anhydroglucose unit is known as substitution degree (SD) whereas molar substitution (MS) indicates the number of propylene oxide moles reacted in each anhydroglucose unit.

It has been demonstrated that HPMC chemical structure, markedly substitution pattern, plays a role in drug release mechanisms (Caccavo et al., 2017), hydration capacity (Arai \& Shikata, 2017; Caccavo et al., 2017), and emulsion-stabilizing ability (Shimada, Fonseca, \& Petri, 2017). We therefore hypothesized that substitution degree and molecular weight also affect the physical-mechanical properties of freestanding thin films. Larsson, Viridén, Stading, and Larsson (2010) have shown that substitution pattern affects glass transition temperature and water plasticization of HPMC-based films, while Espinoza-Herrera, Pedroza-Islas, San Martín-Martinez, Cruz-Orea, and Tomás (2011) studied the thermal, mechanical, and microstructural properties of different cellulose derivative films, including HPMC. However, to the best of our knowledge, no previous studies set out to investigate the effect of HPMC SD and molecular weight on the most important technical aspects of films intended for food packaging applications, i.e., mechanical and water barrier properties. In this context, this contribution aimed at using HPMC grades of different SDs and molecular weights to produce films as well as to study aspects related to physical-mechanical properties and barrier to moisture in an effort to correlate the chemical structure with the properties and performance of the resulting materials. Rheological, thermal, spectroscopic, and water sorption experiments were also carried out to further support these correlations.

\section{Experimental}

\subsection{Materials}

Three HPMC (CAS No. 9004-65-3; EU No. E464; INS No. 464; NAS No. 0534) grades were kindly donated by The Dow Chemical Company (São Paulo, Brazil): Methocel $^{\circledR}$ E15 (average methoxyl content/hydroxypropyl content (M/HP): 3.05), Methocel ${ }^{\oplus}$ KM (average M/HP: 2.26), and Methocel $^{\circ}$ E4M (average M/HP: 3.05). The SD, MS, and methoxyl and hydroxypropyl contents of the HPMC grades are compiled in Table 1. Ultrapure water $(\rho=18.2 \mathrm{M} \Omega \mathrm{cm})$, deionized on a Milli-Q system (Barnstead Nanopure Diamond, USA), was used in all experiments. Hydroxypropyl cellulose (HPC) samples having weight average molecular weights of 12,$000 ; 20,500 ; 50,500 ; 86,300 ; 153,500$; 205,600; 388,000; 637,000; and 865,000 $\mathrm{g} \mathrm{mol}^{-1}$ were purchased from American Polymer Standards Co. (Mentor, OH, USA).

\subsection{Molecular weight}

The molecular weights of the different HPMC grades were determined through high-performance size exclusion chromatography (HP-SEC) on a liquid chromatograph (model SCL-10A, Shimadzu Co.,
Japan) equipped with differential refractive index detector (model RID20A, Shimadzu Co.) and UV-vis spectrophotometric detector (model SPD-10AV, Shimadzu Co.). The mixture $\mathrm{NaNO}_{3} 0.1 \mathrm{M}$ /ethylene glycol $0.1 \%$ was used as eluent. A $50 \mathrm{~mm} \times 6 \mathrm{~mm}(10 \mu \mathrm{m})$ pre-column (Shodex OHpak KB-G) as well as two $8 \mathrm{~mm} \mathrm{ID} \times 300 \mathrm{~mm}(13 \mu \mathrm{m})$ columns (Shodex OHpak KB-806 M) were associated in series, filled with poly(hydroxy methacrylate) gel, and used in HP-SEC runs. Standard HPC, cellobiose, glucose, and ethylene glycol samples were used to build a standard curve. Runs were performed with injection volume of $20 \mu \mathrm{L}$, temperature of $35^{\circ} \mathrm{C}$, and flow equal to $1.0 \mathrm{~mL} \mathrm{~min}^{-1}$. Data acquisition and treatment were carried out in CLASS-LC10 software (version 1.21).

\subsection{Rheological measurements}

Aqueous HPMC solutions at 1, 2 or $3 \%$ (wt.) were analyzed on a rotational rheometer (model MCR 301, Anton Paar GmbH, Austria) operating with concentric cylinder geometry (DG26.7) and in steady shear rates ranging from 0.01 to $10,000 \mathrm{~s}^{-1}$, at $20^{\circ} \mathrm{C}$.

\subsection{Film casting}

HPMC powders were solubilized in distilled water under magnetic stirring for $12 \mathrm{~h}$ to form $2 \%$ (wt.) film-forming solutions (FFS). The solutions were degassed under vacuum and spread with a controlled thickness over level poly(ethylene terephthalate) supports, where they were allowed to dry at $25 \pm 2{ }^{\circ} \mathrm{C}$ for $24 \mathrm{~h}$. Dried films were equilibrated at $50 \% \mathrm{RH}$ for at least $48 \mathrm{~h}$ prior to testing.

\subsection{Fourier-transform infrared spectroscopy (FT-IR)}

The infrared spectra of HPMC films were obtained on a FT-IR spectrometer (model VERTEX 70, Bruker Optik GmbH, Germany) equipped with an ATR module and operating in reflectance mode. The samples were screened within the spectral region from 4000 to $600 \mathrm{~cm}^{-1}$ with a resolution of $2 \mathrm{~cm}^{-1}$.

\subsection{Thermogravimetry}

Film samples (5-6 mg) were accurately weighed in a platinum pan and heated from 25 to $600{ }^{\circ} \mathrm{C}$ at a rate of $10{ }^{\circ} \mathrm{C} \mathrm{min}^{-1}$, within an atmosphere comprising synthetic air $\left(21 \% \mathrm{O}_{2}\right)$ flowing at $40 \mathrm{~mL} \mathrm{~min}^{-1}$. Sample weight was monitored by a high-precision balance within an atmosphere comprising nitrogen flowing at $60 \mathrm{~mL} \mathrm{~min}^{-1}$ as a function of temperature on a TA Q500 (TA Instruments, Inc., New Castle, USA) equipment in order to obtain thermogravimetric (TG) and derivative TG (DTG) curves.

\subsection{Differential scanning calorimetry (DSC)}

Film samples (3-4 mg) were precisely weighed in aluminum pans and heated from -80 to $240{ }^{\circ} \mathrm{C}$ at a rate of $10^{\circ} \mathrm{C} \mathrm{min}^{-1}$, in an atmosphere with nitrogen flowing at $50 \mathrm{~mL} \mathrm{~min}^{-1}$. Heat flow was monitored as a function of temperature on a DSC Q100 (TA Instruments, Inc.) calorimeter.

Table 1

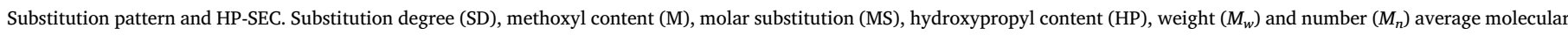
weights, and polydispersity indexes $\left(M_{w} / M_{n}\right)$ of different hydroxypropyl methylcellulose (HPMC) grades.

\begin{tabular}{|c|c|c|c|c|c|c|c|}
\hline HPMC & SD & M (\%) & MS & HP (\%) & $M_{w}\left(\mathrm{~g} \mathrm{~mol}^{-1}\right)$ & $M_{n}\left(\mathrm{~g} \mathrm{~mol}^{-1}\right)$ & $M_{w} / M_{n}$ \\
\hline Methocel $^{\circledast}$ E15 & 1.9 & $28-30$ & 0.23 & $7-12$ & 51,097 & 15,481 & 3.30 \\
\hline Methocel $^{\circ}$ E4M & 1.9 & $28-30$ & 0.23 & $7-12$ & 351,490 & 80,890 & 4.35 \\
\hline Methocel $^{\circ} \mathrm{K} 4 \mathrm{M}$ & 1.4 & $19-24$ & 0.21 & $7-12$ & 331,893 & 75,211 & 4.41 \\
\hline
\end{tabular}




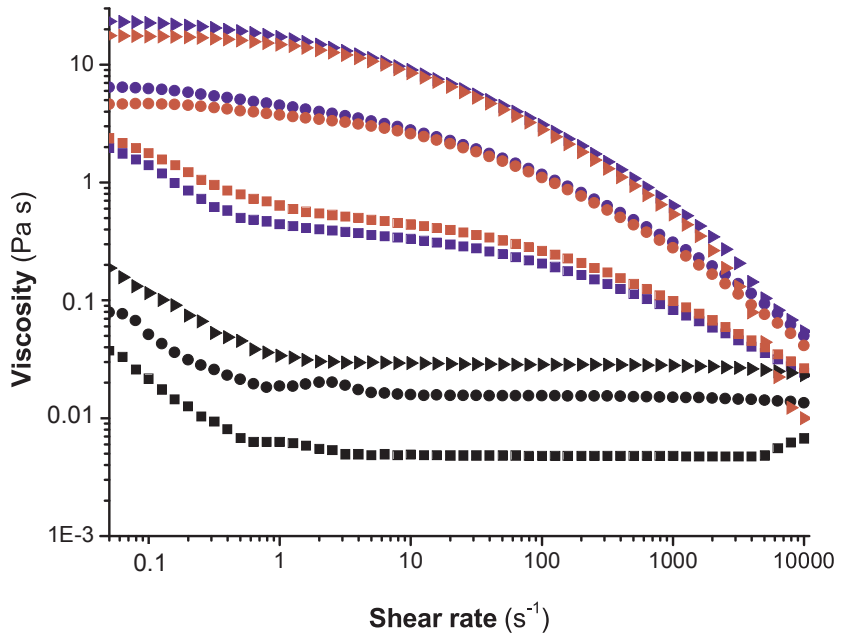

Fig. 1. Rheological aspects. Steady shear viscosity of aqueous solutions comprising $1(\mathbb{\square})$, $2(\bullet)$ or $3 \%(\downarrow)\left(\mathrm{m} \mathrm{v}^{-1}\right)$ of hydroxypropyl methylcellulose Methocel ${ }^{\circ}$ E15 (black), HPMC Methocel $^{\circ}$ E4M (red) or HPMC Methocel ${ }^{\circ}$ K4M (blue) - shear stress versus shear rate curves are presented in Supplementary Fig. S2. (For interpretation of the references to colour in this figure legend, the reader is referred to the web version of this article.)

\subsection{Mechanical properties}

Films were shaped in at least six specimens per treatment according with ASTM D882-12 (ASTM, 2012) and submitted to uniaxial tensile test. Films were stretched at $10 \mathrm{~mm} \mathrm{~min}^{-1}$ by flat grips initially separated by $100 \mathrm{~mm}\left(L_{o}\right)$ on a DL3000 universal testing machine (EMIC Equipamentos e Sistemas de Ensaio Ltda., São José dos Pinhais, Brazil) equipped with a 10-kgf load cell. The mechanical attributes engineering tensile strength $\left(\sigma_{\mathrm{T}}\right)$, percent elongation at break $\left(\varepsilon_{R}\right)$, and Young's modulus (E) were determined by Eqs. (1)-(3), respectively, wherein F, $\mathrm{L}$, and $\mathrm{A}_{0}$ are the maximum load, the ultimate specimen extension (at break), the initial specimen cross-sectional area (i.e., width * thickness). Thickness was taken as the average of at least three random measurements throughout sample gauge length, measured to the nearest $0.001 \mathrm{~mm}$ with a digital micrometer (Mitutoyo Corp., Kanogawa, Japan).

$\sigma_{T}=F / A_{0}$

$\varepsilon_{R}=\left[\left(L-L_{0}\right) / L_{0}\right] \cdot 100$

$E=\lim _{L \rightarrow 0} \sigma / L$

Dynamic mechanical thermal analyses have been performed to provide further insights on the mechanical and thermal behaviors of HPMC films. Rectangular (12.0-13.0 mm in length, $6.4-6.8 \mathrm{~mm}$ in width, and $0.023-0.033 \mathrm{~mm}$ in thickness) specimens were stretched in oscillatory mode at amplitude of $0.1 \%$ and frequency of $1 \mathrm{~Hz}$ on a DMA Q800 (TA Instruments, Inc.) operating at tension mode with temperature ramping at $2^{\circ} \mathrm{C} \mathrm{min}^{-1}$ from -60 to $250{ }^{\circ} \mathrm{C}$.

\subsection{Water vapor permeability (WVP)}

WVP was determined in accordance with the gravimetric modified cup method based on ASTM E96-92 (McHugh, Avena-Bustillos, \& Krochta, 1993). Films were shaped into circles and sealed with silicone grease onto poly(methyl methacrylate) (PMMA) cups having 19.6- $\mathrm{cm}^{2}$ openings that were then topped with symmetrically screwed, open PMMA rings. Test cups were filled with $6 \mathrm{~mL}$ of distilled water and placed in cabinets with controlled $\mathrm{RH}$ (lower than $30 \%$, maintained with silica) and temperature $\left(30 \pm 1{ }^{\circ} \mathrm{C}\right)$. After steady state of water vapor transmission rate was reached, cups were periodically weighed within $24 \mathrm{~h}$ in 2-h intervals. At least four replicates of each film were used for WVP determination.

\subsection{Dynamic vapor sorption (DVS)}

Adsorption/desorption isotherms in/from HPMC films were obtained at $25^{\circ} \mathrm{C}$ on a DVS- 1 system (Surface Measurement Systems Ltd., USA). Films were previously dehydrated in desiccators at $25^{\circ} \mathrm{C}$ and the weights of $c a$. 5-mg samples were monitored while $\mathrm{RH}$ was varied from 0 to $98 \%$ and then from 98 to $0 \%$ in $7 \%$ intervals.

\subsection{Statistical treatment of data}

Quantitative data were submitted to analysis of variance followed by Tukey's mean comparison test, both at $5 \%$ of significance.

\section{Results and discussion}

\subsection{Molecular weight and rheological aspects}

The size and size distribution of HPMC chains were determined by HP-SEC. The obtained standard curve was $M_{W}=5.322 \cdot 10^{-4}$ $(10-t)^{3}+2.295 \cdot 10^{-3} \quad(x-10)^{2}-03644 \quad(x-10)+7.3559 ;$ $R^{2}=0.9983$, wherein $M_{W}$ is the logarithm of the molecular weight - in $\mathrm{g}-$ and $t$ is retention time - in min. The obtained chromatograms are presented in Supplementary Fig. S1, whereas molecular weight data are compiled in Table 1.

It can be observed that HPMC Methocel $^{\circ}$ E4 M and Methocel ${ }^{\circledR}$ K4M have remarkably longer chains than HPMC Methocel ${ }^{\circ}$ E15. Indeed, the designations 15 and $4 \mathrm{M}$ are related to the viscosities of $2 \%\left(\mathrm{w} \mathrm{v}^{-1}\right)$ aqueous HPMC solutions at $20^{\circ} \mathrm{C}$, as disclosed by the manufacturers: $12-18$ and $3000-5600 \mathrm{mPa}$ s. This is in accordance with the rheological behaviors of the HPMC solutions produced here (Fig. 1), which in turn are direct consequences of their molecular weights.

As expected, solutions comprising higher HPMC contents presented greater steady shear viscosity, regardless of the HPMC grade. SD affected the steady shear viscosity, which can be attributed to branching and intermolecular interactions that have been demonstrated to affect the flow behavior of cellulose derivatives (Borges et al., 2015). Molecular weight, in turn, had a pronounced effect on the steady shear viscosity of HPMC solutions, particularly at low shear rates. This is indicated by the steady shear viscosity values of solutions comprising longer HPMC chains, which are $c a$. two orders of magnitude greater than their shorter analogues (Fig. 1). Longer chains experience greater entanglement levels, being capable of offering resistance to flow and, therefore, leading to increased viscosity. It is also noteworthy the shear thinning-to-Newtonian transition in HPMC Methocel ${ }^{\circledR}$ E15. At low shear rates, the highly entangled chains of polymer solutions offer high resistance to flow, resulting in high viscosity. As shear rates increase, the macromolecules are gradually unraveled, bringing about shear thinning behavior. At sufficient shear levels, entanglements are scarce and chains are aligned towards flow direction, situation in which polymer solutions may present Newtonian behavior. Provided that it is easier to disentangle shorter chains, this transition was exclusively observed in HPMC Methocel $^{\circ}$ E15 because of its lower molecular weight.

\subsection{Fourier-transform infrared spectroscopy (FT-IR)}

Fig. 2 shows the FT-IR spectra of the HPMC films. All spectra presented bands close to $2900 \mathrm{~cm}^{-1}$ (at 2972, 2902, and $2836 \mathrm{~cm}^{-1}$, more specifically) attributed to the axial deformation of the $\mathrm{C}-\mathrm{H}$ bonds in aliphatic chains (Sakata \& Yamaguchi, 2011), that is, to $-\mathrm{CH}_{3}$ arising from the substitution of hydroxyl groups by methoxyl and hydroxypropyl ones. Absorptions related to the axial deformation of $\mathrm{C}-\mathrm{O}-\mathrm{C}$ bonds, typical in cellulose ethers, may be observed from 900 to $1300 \mathrm{~cm}^{-1}$ (Anuar, Wui, Ghodgaonkar, \& Taib, 2007; Zaccaron, Oliveira, Guiotoku, Pires, \& Soldi, 2005). Bands at wavenumbers ranging from 1250 to $1460 \mathrm{~cm}^{-1}$ (herein observed at $1315,1374,1410$, and $1452 \mathrm{~cm}^{-1}$ ) are assigned to the angular deformation of $\mathrm{C}-\mathrm{H}$ bonds 


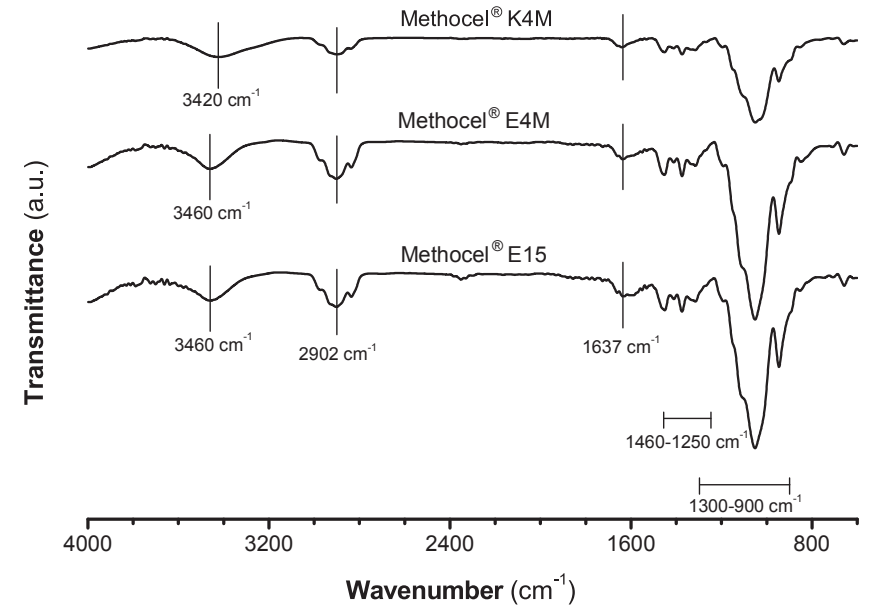

Fig. 2. Fourier-transform infrared spectroscopy (FT-IR). FT-IR absorption spectra of films based on different hydroxypropyl methylcellulose grades.

within $-\left(\mathrm{CH}_{2}\right)_{\mathrm{n}}-$ chains (Sakata \& Yamaguchi, 2011). The band close to 1645 (Zaccaron et al., 2005) and $1650 \mathrm{~cm}^{-1}$ (Anuar et al., 2007), herein observed at $1637 \mathrm{~cm}^{-1}$, is related with the axial deformation of carbonyl groups present in the glucose unit of cellulose.

Although similar, these spectra have differences, such as the band at $3420 \mathrm{~cm}^{-1}$ corresponding to the axial deformation of $\mathrm{O}-\mathrm{H}$ bonds in HPMC Methocel K4M (Zaccaron et al., 2005). The shift of this band towards higher wavenumbers $-c a .3460 \mathrm{~cm}^{-1}-$ in the other samples suggests the weakening of the hydrogen bond interaction network (Banks, Sammon, Melia, \& Timmins, 2005), provided that the former has a higher occurrence of hydroxyl groups. This is supported by the broader band presented by the less substituted grade, i.e., HPMC Methocel $^{\circledast}$ K4M (Sakata \& Yamaguchi, 2011).

\subsection{Thermal properties}

The TG and DTG curves of the produced films show three well defined weight loss stages (Fig. 3).

The first stage took place between 30 and $100{ }^{\circ} \mathrm{C}$, with maximum weight loss rates at $51-60{ }^{\circ} \mathrm{C}$. It is attributed to intermolecular dehydration, i.e., physical desorption of free moisture within the hygroscopic matrix (Ford, 1999; Li, Huang, \& Bai, 1999). Films based on Methocel $^{\circ}$ E15 and Methocel $^{\circ}$ E M grades presented weight losses not higher than $1 \%$ at this stage, whereas those based on HPMC Methocel ${ }^{\circ}$ K4M lost $4.7 \%$ of their original masses (the DTG peak temperatures and sample weights after each weight loss stage are presented in Supplementary Table S1). This reflects the higher equilibrium moisture of the less substituted sample, which therefore comprise a higher hydroxyl content. Feller and Wilt (1990) stated that, for films based on cellulose ethers, the lower the SD, the greater the equilibrium moisture. This was corroborated by determinations of the moisture contents of HPMCbased films at $105^{\circ} \mathrm{C}$ in oven drying until constant weight was achieved: Methocel ${ }^{\circ}$ K4M $(20.6 \pm 1.8 \%)$ was higher $(p<0.05)$ than Methocel $^{\circ}$ E4M $(7.0 \pm 0.2 \%)$ and Methocel $^{\circ}$ E15 $(9.3 \pm 2.4 \%)$, the latter not differing among themselves $(p>0.05)$.

The films were thermally stable up to $c a .200^{\circ} \mathrm{C}$, when the second weight loss stage began, although the weight loss rates were maximum at much higher temperatures: $330-345^{\circ} \mathrm{C}$. This stage may be assigned to the oxidative decomposition of cellulose ethers, involving simultaneous processes of intramolecular dehydration and demethylation (Li et al., 1999; Yin, Luo, Chen, \& Khutoryanskiy, 2006). Finally, at temperatures higher than $400{ }^{\circ} \mathrm{C}$, the compounds resulting from the thermal cleavage or scission at the previous stage (which implied in $c a$. 83-87\% weight loss) underwent thermal oxidation and ignition ( $\mathrm{Li}$ et al., 1999).

As shown in Fig. 3, three endothermal events were identified when HPMC films were heated. The first thermal event at $c a .-18^{\circ} \mathrm{C}$ may be related to either i) the melting of water that is weakly linked to polymer chain (type II water) and that presents remarkable supercooling, therefore freezing and thawing at low temperatures (Ford, 1999) or ii) secondary thermal transitions, i.e., the onset of conformational changes (rotation, particularly) in small segments of the main chain as well as in side groups (Gómez-Carracedo, Alvarez-Lorenzo, Gómez-Amoza, \& Concheiro, 2003). The ductile behaviors of the films (Fig. 4) assayed at temperatures lower than their glass transitions temperatures support the second hypothesis.

The subsequent thermal event showed maximum heat flows between 80 and $100{ }^{\circ} \mathrm{C}$ and is attributed to the evaporation of moisture adsorbed to the highly hydrophilic films. This has been previously reported for HPMC samples (Ford, 1999). The peak temperatures $\left(T_{\max }\right)$ as well as the areas of the endothermic peaks $(\Delta H)$, presented in Supplementary Table S1, correlate well with equilibrium moisture, corroborating this hypothesis. Considering water enthalpy of vaporization $\left(2257 \mathrm{~J} \mathrm{~g}^{-1}\right)$, sample weight, and the area of the endothermic peaks, the amount of water evaporated can be calculated: HPMC Methocel ${ }^{\circ}$ K4M: 15.8\%; HPMC Methocel ${ }^{\circ}$ E4M: 10.3\%; HPMC Methocel ${ }^{\circ}$ E15: $9.5 \%$. These data correlate well with those obtained in oven drying at $105^{\circ} \mathrm{C}$, follow the same trend of those obtained in TG, and are again a consequence of the higher occurrence of hydroxyl groups in HPMC Methocel $^{\circledR} \mathrm{K} 4 \mathrm{M}$, leading to greater water holding capacity.
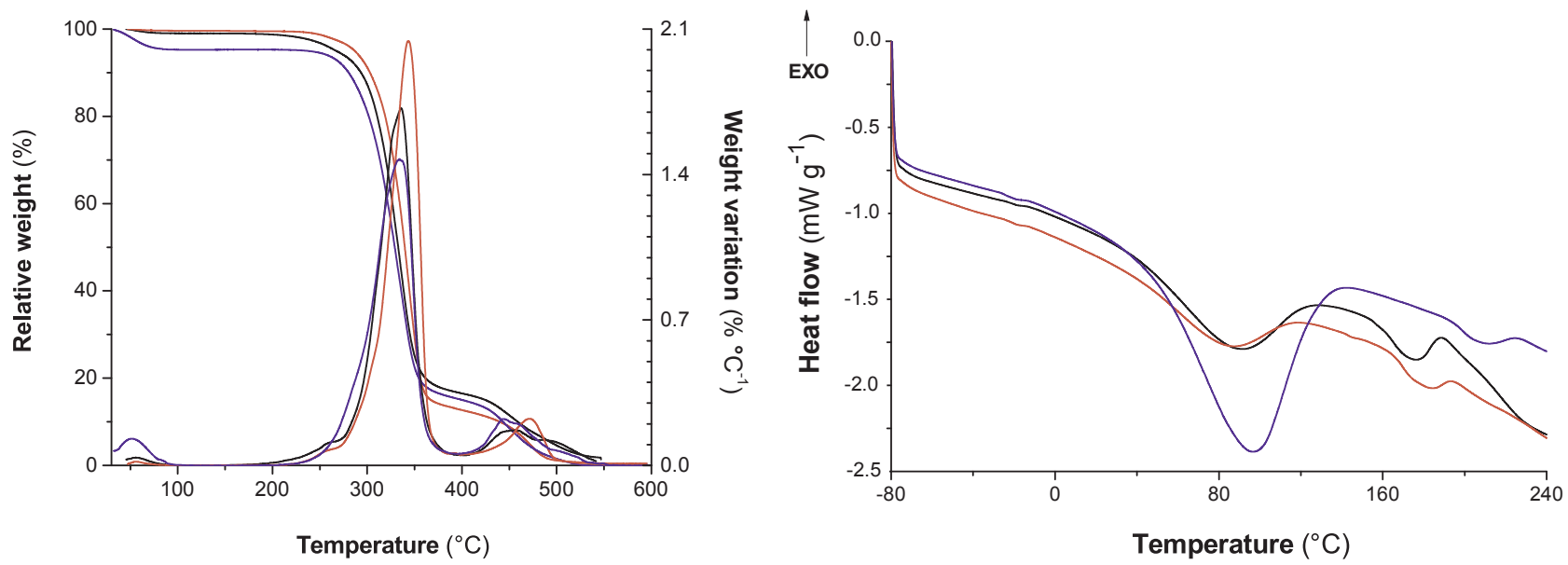

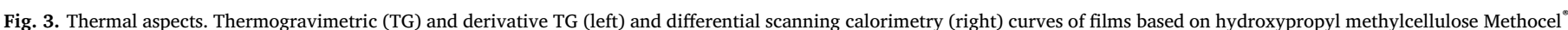

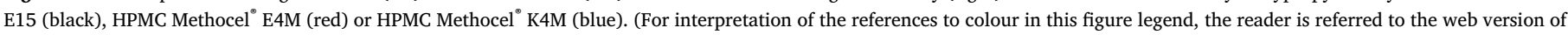
this article.) 


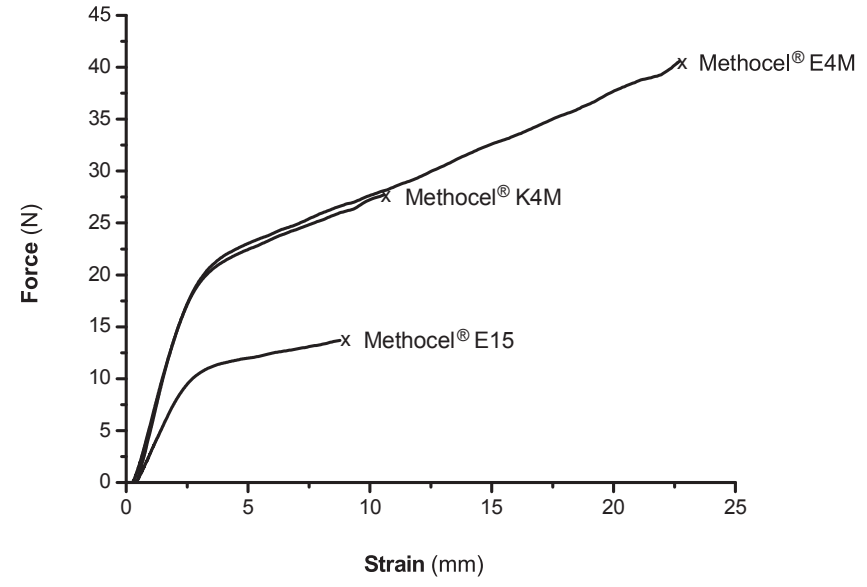

Fig. 4. Uniaxial tensile test. Typical mechanical behaviors of films based on different hydroxypropyl methylcellulose grades evidencing their ductile behaviors upon stretching.

The third thermal event was assigned to the glass transition of the samples. The glass transition temperature $\left(T_{g}\right)$, taken as the average among the onset and offset temperatures, was higher in films based on HPMC Methocel ${ }^{\circ} \mathrm{K} 4 \mathrm{M}\left(T_{g}=207.9^{\circ} \mathrm{C}\right)$ than in films based on HPMC Methocel $^{\circ}$ E4 M $\left(T_{g}=176.5^{\circ} \mathrm{C}\right)$ and HPMC Methocel $^{\circ}$ E15 $\left(T_{g}=172.4^{\circ} \mathrm{C}\right)$. These values are similar to those previously reported in the literature: $172-175^{\circ} \mathrm{C}$ for HPMC Methocel ${ }^{\circ}$ E15 (Masilungan \& Lordi 1984); $191-196^{\circ} \mathrm{C}$ for HPMC Methocel ${ }^{\circ} \mathrm{K} 4 \mathrm{M}$ (Gómez-Carracedo et al., 2003; Nyamweya \& Hoag, 2000); and $162-184^{\circ} \mathrm{C}$ for HPMC Methocel $^{\circ}$ E4M (Gómez-Carracedo et al., 2003; McPhillips, Craig, Royall, \& Hill, 1999). The slightly higher $T_{g}$ of films based HPMC Methocel $^{\circ}$ E4M when compared to those made up of HPMC Methocel ${ }^{\circ}$ E15 is a consequence of the longer chains of the former (Table 1), which feature lower free volume available for conformational changes and thus requiring higher energy input for chains to acquire mobility. The remarkably higher $T_{g}$ of films based on HPMC Methocel ${ }^{\circ}$ K4M are attributed to the lower SD of such grade, as the higher hydroxyl content leads to increased intermolecular interaction through hydrogen bonds (Gómez-Carracedo et al., 2003).

\subsection{Mechanical properties}

The mechanical attributes of the studied HPMC films are summarized in Table 2, whereas their typical mechanical profiles upon testing are presented in Fig. 4.

Films based on HPMC Methocel ${ }^{\circ}$ E4M were remarkably more resistant and extensible $(p<0.05)$ than those made up of HPMC Methocel ${ }^{\oplus}$ E15. This is a consequence of the longer chains of the former (Table 1), implying more molecules among the few crystalline domains and leading to a stronger anchoring effect on the aggregate state. As a result, the resistance, extensibility, and toughness of the material are increased. The greater level of physical entanglement arising from the longer chains of HPMC Methocel ${ }^{\circ}$ E4M also contribute to the improved mechanical resistance of its films when compared to those based on grades of lower molecular weights.

HPMC Methocel ${ }^{\oplus}$ E4M-based films also presented higher tensile strength $(p<0.05)$ than those made up of HPMC Methocel ${ }^{\circledR}$ K4M. This is attributable to the steric effect that methoxyl groups provide HPMC chains with, once they are bulkier than the original hydroxyl groups. This anchor-like action required a higher input of mechanical energy to break the films during a tensile assay, explaining the increased tensile strength.

Young's modulus was not influenced by SD once this mechanical property was equal $(p>0.05)$ for films made up of HPMC Methocel ${ }^{\circ}$ E4M and Methocel ${ }^{\circ}$ K4M. Molecular weight, on the other hand, affected Young's modulus, as suggested by the stiffer $(p<0.05)$ films based on HPMC Methocel ${ }^{\circ}$ E4M in comparison to those made up of Methocel ${ }^{\circ}$ E15. Again, longer polymer chains tend to experience decreased free volume and, as a consequence, limited mobility. In this sense, deformation is hampered, especially at the predominantly elastic region of the viscoelastic regime, leading to increased Young's modulus. Oscillatory tests have been carried out to provide further insight on the mechanical and thermal properties of HPMC-based films (Supplementary Fig. S3).

\subsection{Water barrier properties}

The driving force for water vapor diffusion is the $\mathrm{RH}$ gradient from the interior of the test capsules towards chamber atmosphere. Because all capsules were held within the same chamber, the final $\mathrm{RH}$ was equal for all specimens. Therefore, to allow proper comparison, the $\mathrm{RH}$ values inside the capsules must also be the same, condition which was achieved here (Table 2).

Molecular weight did not affect the WVP of HPMC films, whereas SD had a pronounced effect on this variable. Films made up of HPMC Methocel ${ }^{\circ}$ K4M presented higher $(p<0.05)$ WVP values than those based on the more substituted grades. This is a straightforward consequence of the higher occurrence of hydroxyl groups in the former, leading to a higher capacity of interaction with water molecules and, therefore, providing films with increased hydrophilicity. This outcome is in line with the higher affinity to moisture of films based on HPMC Methocel $^{\circ} \mathrm{K} 4 \mathrm{M}$, corroborating the results obtained through oven drying, DSC, and TG.

DVS was carried out to further elucidate the hygroscopicity of the HPMC films. The adsorption and desorption isotherms are presented in Fig. 5.

All films presented affinity to water molecules, as indicated by the higher masses in desorption cycles than in their adsorption analogues for a given RH, leading to hysteresis. This phenomenon is believed to arise from the adsorption of water molecules to hydroxyl groups as well as to different availabilities of these polar groups at different $\mathrm{RH}$ values (Salmén \& Larsson, 2018). At low RH, hydrogen bonding is the main interaction involved in moisture adsorption (Enrione, Hill \& Mitchell, 2007). In this sense, the initial portion of the adsorption curve corresponds to the attachment of water molecules to the hydrophilic groups of the HPMC, notably the hydroxyls. Indeed, in this region, the slopes of the curves assigned to the more substituted HPMC grades (i.e., Methocel $^{\circ}$ E4M and Methocel ${ }^{\circ}$ E15) are similar and lower than that of the less substituted grade (i.e., Methocel $\left.{ }^{\circ} \mathrm{K} 4 \mathrm{M}\right)$. This finding is also in line with WVP data as well as moisture contents determined through oven drying, DCS, and TG. After a certain RH, the isotherms of the E grades

Table 2

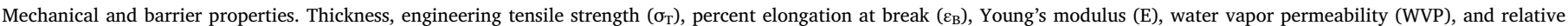
humidity (RH) of films based on different hydroxypropyl methylcellulose (HPMC) grades.

\begin{tabular}{|c|c|c|c|c|c|c|}
\hline HPMC Methocel ${ }^{\circ}$ & Thickness $(\mu \mathrm{m})$ & $\sigma_{\mathrm{T}}(\mathrm{MPa})$ & $\varepsilon_{\mathrm{B}}(\%)$ & $\mathrm{E}(\mathrm{GPa})$ & $W V P\left(\mathrm{~g} \mathrm{~mm} \mathrm{kPa}^{-1} \mathrm{~h}^{-1} \mathrm{~m}^{-2}\right)$ & $R H(\%)$ \\
\hline E15 & $25.0 \pm 3.8^{\mathrm{a}}$ & $30.83 \pm 6.43^{\mathrm{a}}$ & $6.06 \pm 1.56^{\mathrm{a}}$ & $1.45 \pm 0.15^{\mathrm{a}}$ & $0.754 \pm 0.285^{\mathrm{a}}$ & $72.7 \pm 3.4^{\mathrm{a}}$ \\
\hline K4M & $43.5 \pm 3.3^{\mathrm{b}}$ & $52.13 \pm 3.33^{b}$ & $11.89 \pm 1.98^{\mathrm{b}}$ & $1.74 \pm 0.08^{\mathrm{b}}$ & $1.532 \pm 0.164^{\mathrm{b}}$ & $76.1 \pm 1.6^{\mathrm{a}}$ \\
\hline E4M & $30.1 \pm 2.6^{\mathrm{a}}$ & $67.28 \pm 8.39^{c}$ & $17.37 \pm 3.32^{\mathrm{c}}$ & $1.76 \pm 0.16^{\mathrm{b}}$ & $0.923 \pm 0.151^{\mathrm{a}}$ & $76.3 \pm 1.8^{\mathrm{a}}$ \\
\hline
\end{tabular}

${ }^{\mathrm{a}-\mathrm{c}}$ Mean values \pm standard deviations followed by different letters within the same column are significantly different $(p<0.05)$. 


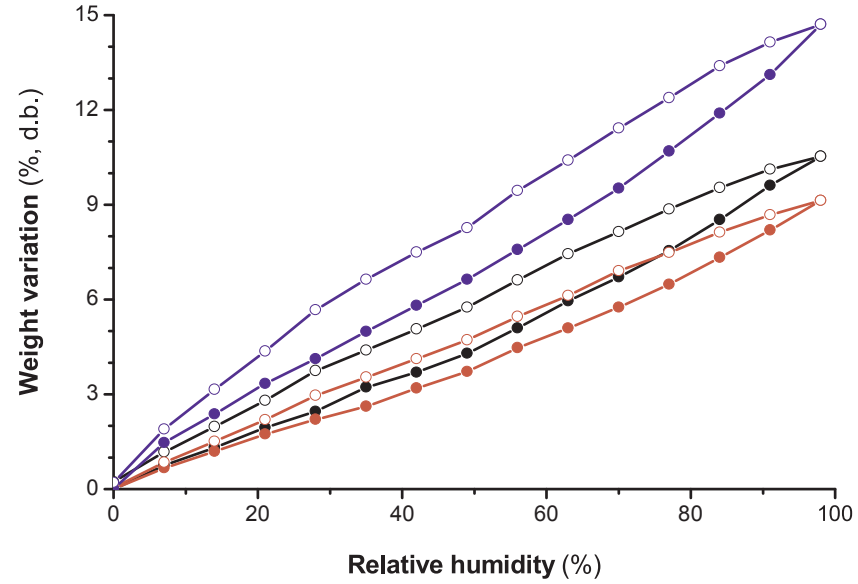

Fig. 5. Dynamic vapor sorption. Adsorption ( $(0)$ and desorption $(O)$ of water vapor in/ from films based on hydroxypropyl methylcellulose Methocel ${ }^{\circ}$ E15 (black), HPMC Methocel $^{\circ}$ E4M (red) or HPMC Methocel ${ }^{\circ}$ K4M (blue). (For interpretation of the references to colour in this figure legend, the reader is referred to the web version of this article.)

Table 3

Dynamic vapor sorption data. Parameters of the Brunauer-Emmett-Teller (BET) and Guggenheim-Anderson-de Boer (GAB) models fitted to films based on different hydroxypropyl methylcellulose (HPMC) grades.

\begin{tabular}{|c|c|c|c|c|c|c|c|}
\hline \multirow[t]{2}{*}{ HPMC } & \multicolumn{3}{|l|}{ BET } & \multicolumn{4}{|l|}{ GAB } \\
\hline & $R^{2}$ & $X_{m}\left(\mathrm{~mol} \mathrm{~g}^{-1}\right)$ & $C_{B E T}$ & $R^{2}$ & $X_{m}\left(\mathrm{~mol} \mathrm{~g}^{-1}\right)$ & $C_{G A B}$ & $K$ \\
\hline E15 & 0.986 & 0.002 & 4.765 & 0.946 & 0.004 & 0.513 & 4.76 \\
\hline K4M & 0.994 & 0.003 & 5.683 & 0.986 & 0.005 & 0.512 & 6.20 \\
\hline E4M & 0.987 & 0.002 & 3.799 & 0.913 & 0.004 & 0.489 & 3.70 \\
\hline
\end{tabular}

diverge because moisture adsorption is no longer driven by the occurrence of hydrophilic groups, but by the swelling capacity of the polymer (Fringant et al., 1996).

The models that best fitted the experimental data were BrunauerEmmett-Teller (BET), for water activity $\left(\boldsymbol{a}_{\boldsymbol{w}}\right)$ values ranging from 0.07 to 0.35 (Eq. (4)), and Guggenheim-Anderson-de Boer (GAB), for $\boldsymbol{a}_{\boldsymbol{w}}=0.07-0.84$ (Eq. (5)). The correlation coefficients $\left(R^{2}\right)$ as well as the parameters adjusted to each model are presented in Table 3.

$\Delta \mathrm{m}=\frac{X_{m} C_{B E T} a_{w}}{\left(1-a_{w}\right)\left(1-a_{w}+C_{B E T} a_{w}\right)}$

$\Delta \mathrm{m}=\frac{X_{m} C_{G A B} K a_{w}}{\left(1-K a_{w}\right)\left(1-K a_{w}+C_{G A B} K a_{w}\right)}$

In the aforementioned equation, $\Delta \mathrm{m}$ is weight variation (\%) at a given $a_{w}, X_{m}$ is the value of the monolayer (\%, dry basis), $C_{B E T}$ is a constant dependent on the temperature, $C_{G A B}$ is a constant that is related with the binding energy among water molecules and the monolayers, and $K$ is a constant that depends upon the temperature and is related with the sorption heat of the monolayer (Imran, El-Fahmy, Revol-Junelles, \& Desobry, 2010).

The $X_{m}$ values, which are related to the water strongly adsorbed to specific hydrophilic sites (Imran et al., 2010) and were found to be greater for films based on HPMC Methocel ${ }^{\circ} \mathrm{K} 4 \mathrm{M}$ regardless of the model, corroborate the above discussion concerning the initial slope of the moisture adsorption isotherms. Another indicative of the stronger interaction of moisture with this HPMC grade is the greater $C_{B E T}$ value when compared to the other grades, suggesting higher bonding energy (Imran et al., 2010).

\section{Conclusions}

In summary, we confirmed our hypothesis that both chain length and backbone pendant group affected the mechanical and water barrier properties of HPMC films. Thermal and rheological properties also showed influence of HPMC chemical structure. SD had a pronounced effect on the affinity and barrier to moisture, glass transition, tensile resistance, and extensibility of HPMC films. This effect has been attributed to the reduced polarity provided by methoxyl substitution. Molecular weight, in turn, affected mostly the rheological behavior of HPMC solutions as well as the mechanical properties of its films. This outcome arises from the higher level of physical entanglement and reduced free volume of longer chains. Considering food packaging applications, the trend towards more mechanically resistant and less permeable films guide the choice of HPMC Methocel ${ }^{\circledR}$ E4M as the optimum film-forming matrix among the studied HPMC grades. Further studies are suggested to investigate the role played by other substitution degrees as well as hydroxypropyl substitution on the physical-mechanical properties of HPMC-based films.

\section{Funding}

This work was supported by São Paulo Research Foundation (FAPESP) [grant numbers 2013/14366-7 and 2014/23098-9]; and National Council for Scientific and Technological Development (CNPq) [grant number 402287/2013-4].

\section{Acknowledgements}

The authors are thankful to the financial support given by FAPESP (grants \#2013/14366-7 and 2014/23098-9), CNPq, SISNANO/MCTI, FINEP, CAPES (grant \#33001014005D-6), and Embrapa AgroNano research network. They are also thankful to the experimental support by Beatriz Lodi. Prof. Elisabete Frollini (IQSC/USP) is acknowledged for HP-SEC experiments. Dr. Roberto Avena-Bustillos and Dr. Tara McHugh (WRRC/ARS/USDA) are also acknowledged for DVS runs. Finally, the authors thank Paulo Martins at The Dow Chemical Company for kindly providing Methocel $^{\circledR}$ samples.

\section{Appendix A. Supplementary data}

Supplementary data associated with this article can be found, in the online version, at https://doi.org/10.1016/j.carbpol.2018.01.016.

\section{References}

ASTM D882-12 (2012). Standard test method for tensile properties of thin plastic sheeting. West Conshohocken, PA: ASTM International12. http://dx.doi.org/10.1520/ D0882-12.

Alzate, P., Miramont, S., Flores, S., \& Gerschenson, L. N. (2017). Effect of the potassium sorbate and carvacrol addition on the properties and antimicrobial activity of tapioca starch hydroxypropyl methylcellulose edible films. Starch - Stärke, 69(5--6), 1600261.

Anuar, N. K., Wui, W. T., Ghodgaonkar, D. K., \& Taib, M. N. (2007). Characterization of hydroxypropylmethylcellulose films using microwave non-destructive testing technique. Journal of Pharmaceutical and Biomedical Analysis, 43(2), 549-557.

Arai, K., \& Shikata, T. (2017). Hydration/dehydration behavior of cellulose ethers in aqueous solution. Macromolecules, 50(15), 5920-5928.

Azeredo, H. M. C., \& Waldron, K. W. (2016). Crosslinking in polysaccharide and protein films and coatings for food contact - A review. Trends in Food Science \& Technology, $52,109-122$.

Banks, S. R., Sammon, C., Melia, C. D., \& Timmins, P. (2005). Monitoring the therma gelation of cellulose ethers in situ using attenuated total reflectance Fourier transform infrared spectroscopy. Applied Spectroscopy, 59(4), 452-459.

Bertolino, V., Cavallaro, G., Lazzara, G., Merli, M., Milioto, S., Parisi, F., \& Sciascia, L. (2016). Effect of the biopolymer charge and the nanoclay morphology on nanocomposite materials. Industrial \& Engineering Chemistry Research, 55(27), 7373-7380.

Borges, A. F., Silva, C., Coelho, J. F. J., \& Simões, S. (2015). Oral films: current status and future perspectives: I - Galenical development and quality attributes. Journal of Controlled Release, 206, 1-19.

Burdock, G. A. (2007). Safety assessment of hydroxypropyl methylcellulose as a food 
ingredient. Food and Chemical Toxicology, 45(12), 2341-2351.

Caccavo, D., Lamberti, G., Barba, A. A., Abrahmsén-Alami, S., Viridén, A., \& Larsson, A. (2017). Effects of HPMC substituent pattern on water up-take, polymer and drug release: An experimental and modelling study. International Journal of Pharmaceutics, 528(1), 705-713.

Cavallaro, G., Donato, D. I., Lazzara, G., \& Milioto, S. (2011). Films of halloysite nanotubes sandwiched between two layers of biopolymer: From the morphology to the dielectric, thermal, transparency, and wettability properties. The Journal of Physical Chemistry C, 115(42), 20491-20498.

Cavallaro, G., Lazzara, G., Konnova, S., Fakhrullin, R., \& Lvov, Y. (2014). Composite films of natural clay nanotubes with cellulose and chitosan. Green Materials, 2(4), 232-242.

Enrione, J. I., Hill, S. E., \& Mitchell, J. R. (2007). Sorption behavior of mixtures of glycerol and starch. Journal of Agricultural and Food Chemistry, 55(8), 2956-2963.

Espinoza-Herrera, N., Pedroza-Islas, R., San Martín-Martinez, E., Cruz-Orea, A., \& Tomás, S. A. (2011). Thermal, mechanical and microstructures properties of cellulose derivatives films: A comparative study. Food Biophysics, 6(1), 106-114.

Feller, R. L., \& Wilt, M. (1990). Evaluation of cellulose ethers for conservation. Research in conservation. Los Angeles: The Getty Conservation Institute.

Ford, J. L. (1999). Thermal analysis of hydroxypropylmethylcellulose and methylcellulose: Powders, gels and matrix tablets. International Journal of Pharmaceutics, 179(2), 209-228.

Fringant, C., Desbrières, J., Milas, M., Rinaudo, M., Joly, C., \& Escoubes, M. (1996). Characterisation of sorbed water molecules on neutral and ionic polysaccharides. International Journal of Biological Macromolecules, 18(4), 281-286.

Gómez-Carracedo, A., Alvarez-Lorenzo, C., Gómez-Amoza, J. L., \& Concheiro, A. (2003). Chemical structure and glass transition temperature of non-ionic cellulose ethers. Journal of Thermal Analysis and Calorimetry, 73(2), 587-596.

Garavand, F., Rouhi, M., Razavi, S. H., Cacciotti, I., \& Mohammadi, R. (2017). Improving the integrity of natural biopolymer films used in food packaging by crosslinking approach: A review. International Journal of Biological Macromolecules, 104, 687-707.

Imran, M., El-Fahmy, S., Revol-Junelles, A.-M., \& Desobry, S. (2010). Cellulose derivative based active coatings: Effects of nisin and plasticizer on physico-chemical and antimicrobial properties of hydroxypropyl methylcellulose films. Carbohydrate Polymers, 81(2), 219-225.

Keary, C. M. (2001). Characterization of METHOCEL cellulose ethers by aqueous SEC with multiple detectors. Carbohydrate Polymers, 45(3), 293-303.

Larsson, M., Viridén, A., Stading, M., \& Larsson, A. (2010). The influence of HPMC substitution pattern on solid-state properties. Carbohydrate Polymers, 82(4), 1074-1081.

Li, X.-G., Huang, M.-R., \& Bai, H. (1999). Thermal decomposition of cellulose ethers.
Journal of Applied Polymer Science, 73(14), 2927-2936.

Masilungan, F. C., \& Lordi, N. G. (1984). Evaluation of film coating compositions by thermomechanical analysis. I. Penetration mode. International Journal of Pharmaceutics, 20(3), 295-305.

McHugh, T. H., Avena-Bustillos, R., \& Krochta, J. M. (1993). Hydrophilic edible films: Modified procedure for water vapor permeability and explanation of thickness effects. Journal of Food Science, 58(4), 899-903.

McPhillips, H., Craig, D. Q. M., Royall, P. G., \& Hill, V. L. (1999). Characterisation of the glass transition of HPMC using modulated temperature differential scanning calorimetry. International Journal of Pharmaceutics, 180(1), 83-90.

Moghimi, R., Aliahmadi, A., \& Rafati, H. (2017). Antibacterial hydroxypropyl methyl cellulose edible films containing nanoemulsions of Thymus daenensis essential oil for food packaging. Carbohydrate Polymers, 175, 241-248.

Nyamweya, N., \& Hoag, S. W. (2000). Assessment of polymer-polymer interactions in blends of HPMC and film forming polymers by modulated temperature differential scanning calorimetry. Pharmaceutical Research, 17(5), 625-631.

Otoni, C. G., Avena-Bustillos, R. J., Azeredo, H. M. C., Lorevice, M. V., Moura, M. R., Mattoso, L. H. C., \& McHugh, T. H. (2017). Recent advances on edible films based on fruits and vegetables - A review. Comprehensive Reviews in Food Science and Food Safety, 16(5), 1151-1169.

Sakata, Y., \& Yamaguchi, H. (2011). Effects of calcium salts on thermal characteristics of hydroxypropyl methylcellulose films. Journal of Non-Crystalline Solids, 357(4), 1279-1284.

Salmén, L., \& Larsson, P. A. (2018). On the origin of sorption hysteresis in cellulosic materials. Carbohydrate Polymers, 182, 15-20.

Shimada, R. T., Fonseca, M. S., \& Petri, D. F. S. (2017). The role of hydroxypropyl methylcellulose structural parameters on the stability of emulsions containing Spirulina biomass. Colloids and Surfaces A: Physicochemical and Engineering Aspects, 529, $137-145$.

Yin, J., Luo, K., Chen, X., \& Khutoryanskiy, V. V. (2006). Miscibility studies of the blends of chitosan with some cellulose ethers. Carbohydrate Polymers, 63(2), 238-244.

Zaccaron, C. M., Oliveira, R. V. B., Guiotoku, M., Pires, A. T. N., \& Soldi, V. (2005). Blends of hydroxypropyl methylcellulose and poly(1-vinylpyrrolidone-co-vinyl acetate): Miscibility and thermal stability. Polymer Degradation and Stability, 90(1), 21-27.

Zhang, X. X., Zhang, W., Tian, D., Zhou, Z. H., \& Lu, C. H. (2013). A new application of ionic liquids for heterogeneously catalyzed acetylation of cellulose under solvent-free conditions. RSC Advances, 3(21), 7722-7725.

Zhang, J., Yang, W., Vo, A. Q., Feng, X., Ye, X., Kim, D. W., et al. (2017). Hydroxypropyl methylcellulose-based controlled release dosage by melt extrusion and 3D printing: Structure and drug release correlation. Carbohydrate Polymers, 177, 49-57. 